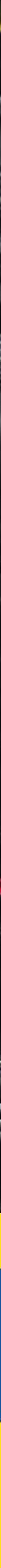

POR SARA REARDON

TRADUCIDO POR DEBBIE PONCHNER

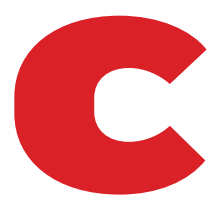

uando empezó a estudiar a las personas que habían aterrorizado a su país, Natalia Trujillo se preparó para encontrarse cara a cara con monstruos.

Entrevistaría a excombatientes del largo y sangriento conflicto que se había apoderado de Colombia por más de 50 años. La compleja lucha de poder entre los insurgentes guerrilleros, el gobierno, los grupos paramilitares y los narcotraficantes había matado a cientos de miles de personas y había desplazado a millones. Cuatro miembros de su familia habían sido secuestrados y la violencia había expulsado a su padre de sus tierras. Algunos de sus colegas habían pasado por experiencias mucho peores.

Trujillo, ahora una experta en neurociencia en la Universidad de Antioquia, en Medellín, estaba interesada en estudiar las raíces psicológicas de la violencia, observando a los combatientes que habían depuesto las armas e intentaban reingresar a la sociedad civil. Su oportunidad llegó en 2010, cuando un programa de reintegración del gobierno reunió, por el día, en el jardín botánico de Medellín, a cientos de excombatientes.

Ella y su equipo de investigación ingresaron al enclave con una batería de pruebas cognitivas, botones de pánico -en caso de que algo saliera mal- y algunas ideas preconcebidas. "Pensé que personas que pueden matar a sus vecinos, que de las FARC tienen la oportunidad de reingresar a la sociedad colombiana. 


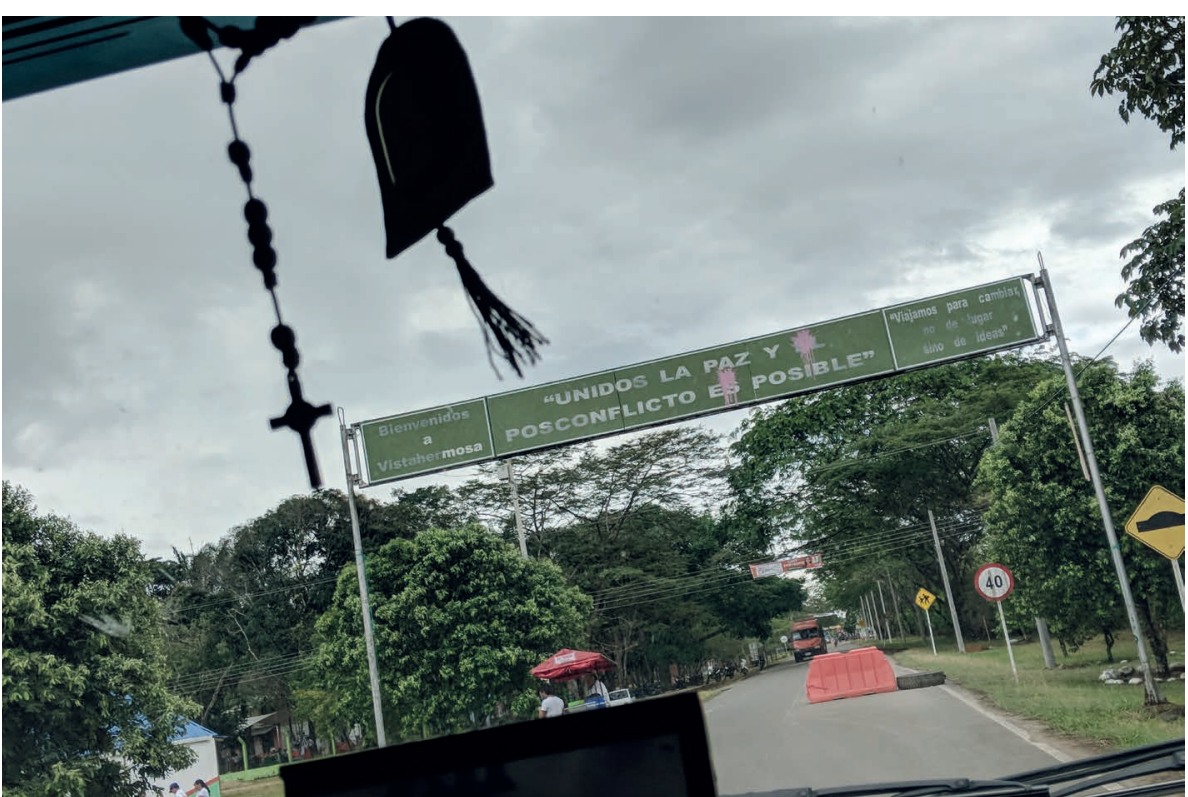

El municipio de Vista Hermosa podría servir como un laboratorio natural para el estudio de la reconciliación.

- pueden destruir sus comunidades, que pueden tener el corazón para obligar a otras personas a abandonar sus fincas, tienen que ser realmente malas", dice Trujillo. Y se encontró con algunos que llenaron sus expectativas.

Con cadenas alrededor de sus cuellos y jactanciosos pavoneos, algunos trataron de intimidar a los investigadores. Pero con mayor frecuencia, los científicos encontraron personas comunes, paseando en el jardín y comiendo helado con sus hijos.

"Al principio estaba bastante decepcionada", dice. Si algo andaba mal en sus cerebros, eso proporcionaría una explicación fácil para toda la maldad que habían hecho. Pero después de estudiar a más de 600 combatientes, ella comenzó a comprender la complejidad de sus experiencias. "Me di cuenta de que no todos son sociópatas. Me di cuenta de que la mayoría de ellos también son víctimas".

Ese reconocimiento ha llevado a Trujillo y a sus colegas a reexaminar no solo sus propios sentimientos acerca de los excombatientes, sino también el enfoque que debe tener el país para lidiar con ellos.

El gobierno de Colombia participa actualmente en uno de los mayores esfuerzos de paz en la historia. Como parte de un tratado de 2016 con el grupo guerrillero de izquierda conocido como las Fuerzas Armadas Revolucionarias de Colombia (FARC), el gobierno otorgará amnistía a los combatientes que abandonen el conflicto y completen un programa de reincorporación, siempre que no hayan cometido delitos graves. Unos 6.800 combatientes de las FARC ya han ingresado al programa.

El esfuerzo, que es políticamente controvertido y se espera que cueste 129,5 billones de pesos colombianos (46 millones de dólares estadounidenses), enfrenta abrumadoras dificultades. Pero también le otorga a los estudios a largo plazo en pueblos que estuvieron plagados por conflictos, para rastrear cómo la cognición y las actitudes podrían cambiar a lo largo del proceso de reconciliación, tanto para los excombatientes como para los civiles. Los datos podrían eventualmente informar los esfuerzos de recuperación de otros países devastados por la guerra.

Pero la investigación también está revelando cuán profundo es el desafío. Y algunos expertos temen que la atención disponible para los excombatientes, mientras tanto, es inadecuada.

"Va a ser increíblemente difícil salir de este círculo vicioso", dice Jiovani Arias, psicoterapeuta y politólogo de la Universidad de los Andes, en Bogotá. Sin inversiones para mejorar la salud mental, dice, el legado de violencia que afecta tanto a excombatientes como a civiles podría torpedear los precarios esfuerzos de paz de Colombia.

\section{EL CAMINO HACIA LA PAZ}

En el momento que un autobús lleno de científicos llega al municipio de Vista Hermosa, en el centro de Colombia, Diana Matallana, neuropsicóloga de la Pontificia Universidad Javeriana, en Bogotá, todavía no puede creer en dónde está. "Hace cinco años, no podías venir aquí", dice. "Es como un símbolo de la parte más dura del conflicto".

El conflicto armado colombiano creció y menguó durante medio siglo mientras varios grupos militares competían por el control del territorio. Los civiles quedaron atrapados en el fuego cruzado: más de 260.000 personas murieron y 7 millones fueron desplazadas durante las décadas de violencia, según un registro gubernamental de víctimas.

La región del Meta, donde se encuentra Vista Hermosa, fue una de las muchas áreas abandonadas por el ejército colombiano en la década de 1990 y dejada para ser gobernada alternativamente por grupos paramilitares y guerrillas. Fue un arreglo tenso. Las guerrillas ayudaron a desarrollar infraestructura, pero no dudaban en matar rápidamente a informantes sospechosos. Los paramilitares, contratados principalmente por los capos de la droga y las élites políticas adineradas, tendían a ser más despiadados, torturaban a supuestos espías y dejaban cadáveres en las puertas de las escuelas. Ambas partes estaban fuertemente involucradas en el tráfico de cocaína y secuestraron a miles de personas a cambio de una recompensa -entre ellos, al hermano de Matallana-.

Desde el acuerdo de paz de 2016, se le ha permitido a los combatientes de las FARC entrar en una campaña de desarme y rehabilitación dirigida por la Agencia de Reincorporación y Normalización de Colombia (ARN), en Bogotá. La ARN había sido establecida años antes, y desde entonces ha facilitado la reintegración de unos 20.000 paramilitares y guerrilleros que abandonaron el conflicto de forma independiente o como parte de otro acuerdo de paz.

La ARN ahora opera 26 asentamientos 
improvisados en toda Colombia, conocidos como zonas de tránsito (ver 'Un conflicto persistente'), para los miembros de las FARC que recién están reingresando a la sociedad. Ofrecen servicios como educación y atención de la salud, también ayudan a proporcionar algo de protección para los excombatientes, que son blanco habitual de antiguos enemigos, de antiguos aliados que se niegan a rendirse, y de civiles. Después de completar un programa, los excombatientes pueden recibir cédulas de identidad que les permite vivir y trabajar legalmente en el país.

La posibilidad de su regreso no emociona a algunos de los residentes de Vista Hermosa. Un letrero en la carretera que dice "Unidos, la paz y el pos-conflicto son posibles" ha sido bombardeado con bolas de pintura rosa. "Alguien no está de acuerdo", comenta uno de los investigadores.

Matallana y Carlos Gómez, un psiquiatra de la Javeriana, planean iniciar un estudio de 10 a 20 años de duración en el que se seguirá a más de 2.000 personas de Vista Hermosa, civiles y excombatientes por igual. "Estamos planeando por primera vez - en Colombia y en el mundo- aprender qué cosas ayudan a lograr la reconciliación", dice Gómez.

El equipo pretende medir factores como el neurodesarrollo en los niños, la cognición social y la regulación emocional en adultos, y la salud mental de todos los participantes para ayudar en el proceso de reintegración. En un proyecto piloto, financiado por fundaciones filantrópicas, han entrevistado a 200 civiles, además de los representantes de 150 excombatientes que viven en una zona tranquila a solo tres horas de distancia. "Necesitamos tener buenos datos para ver cómo está funcionando y para poder hacer intervenciones rápidamente si vemos que el proceso no está funcionando bien", dice Gómez.

Ha sido difícil para los investigadores tanto aquí, como en otros lugares- estudiar si programas como estos pueden evitar que los combatientes vuelvan a la delincuencia, en gran parte porque a menudo es imposible rastrear los resultados de las personas que los atraviesan. "Simplemente asumimos que tiene un efecto, y no tenemos otra opción", dice Enzo Nussio, un experto en ciencias políticas del Instituto Federal Suizo de Tecnología, en Zúrich.

Sin embargo, Nussio y otros tienen esperanzas sobre los resultados en Colombia. El país tiene muchos más recursos para dedicar al esfuerzo que naciones como Burundi y Sudán, que han emprendido esfuerzos similares con poco éxito.

Los excombatientes, mientras tanto, se enfrentan a una mezcla de desafíos -algunos familiares y otros nuevos-. Al igual que los veteranos de otros conflictos, a muchos les resulta difícil estar cerca de personas que no entienden la experiencia del combate, dice Thomas Elbert, psicólogo de la Universidad de Konstanz, en Alemania. Pueden acercarse

\section{Un conflicto persistente}

Un tratado de 2016 está ayudando a poner fin a décadas de violencia entre el gobierno colombiano y las Fuerzas Armadas Revolucionarias de Colombia (FARC), un grupo guerrillero de izquierda. Como resultado, miles de excombatientes de las FARC están ingresando a las denominadas 'zonas de tránsito' conocidas como espacios territoriales para el entrenamiento y la reincorporación (ETCR) que se encuentran en todo el país. En estas zonas, los excombatientes comenzarán un proceso para desmovilizarse y prepararse para el reingreso a la sociedad colombiana. Aún así, hay varios grupos guerrilleros que continúan luchando, incluidos 1.000

'disidentes' de las FARC que se han negado a abandonar sus armas.

Ellos representan un peligro para los excombatientes y un desafío para los esfuerzos de establecimiento de la paz.

- ETCR $\square$ Actividad de los disidentes de FARC

\section{MEDIO SIGLO DE TERROR}

La Base de Datos Globales sobre Terrorismo (Global Terrorism Database) contiene décadas de datos sobre ataques y secuestros iniciados por las FARC, los paramilitares, traficantes de drogas y otros grupos militantes durante la mitad siglo de violencia que se apoderó del país. Estos ataques solo representan una fracción de las 260.000 vidas perdidas en el conflicto a través de los años.

- Muertes a Secuestros

1985

El grupo guerrillero marxista M-19 toma

1,200 ....... el Palacio de Justicia en Bogotá; 89 personas mueren.

1,000

800

1977 La muerte de

600 .... una huelga general de trabajadores envalentonó a los

400 grupos rebeldes y los lleva a capitalizar en la desconfianza 200

\section{9}

El capo de la droga Pablo Escobar ordena el bombardeo del vuelo 203 de Avianca, matando a 107 pasajeros. 
- a otros que han vivido en la violencia, que puede ser peligroso en un lugar como Colombia, donde los narcotraficantes y otros grupos armados todavía operan.

Colombia plantea algunos desafíos únicos, dice Gómez. A diferencia de aquellos que libran guerras civiles en muchos otros lugares, los guerrilleros colombianos no son impulsados por la raza o la religión, sino por ideología política. Reprogramar sus corazones y mentes podría requerir estrategias diferentes a las utilizadas para otros militantes radicalizados, criminales de guerra o asesinos en serie, y nadie sabe cuáles deberían ser esas estrategias.

Gustavo Tovar, presidente del consejo municipal de Vista Hermosa, teme que su pueblo -y el país- no estén listos para la ola de excombatientes. "Colombia está en el medio de esta metamorfosis", dice. "Nosotros entramos en ella sin saber lo que estamos haciendo".

\section{EL PESO DEL PASADO}

$\mathrm{Al}$ oeste de Meta se encuentra el Valle del Cauca, una región agrícola casi plana rodeada de montañas. Aquí, en un hotel lujoso con vistas a viñedos y plantaciones de caña de azúcar, el excomandante de las FARC Juan Carlos Sánchez está viendo vídeos en una computadora portátil. Diseñados para la investigación, los vídeos presentan diferentes tipos de altercados: una discusión entre dos personas, alguien que es golpeado por una silla, una persona que le mete una puñalada en la espalda a otro.

Sánchez se unió a la guerrilla en 1998 cuando vivía en Meta. No fue completamente por elección propia, dice. Cuando los militares colombianos abandonaron la región, las FARC se convirtieron en el gobierno de facto. La guerrilla persuadió a los locales para que se armaran en caso de que regresaran los paramilitares y el gobierno, diciéndoles que esta era la única forma de proteger a sus familias. Eventualmente, Sánchez se unió al grupo oficialmente.

Al principio, dice, los guerrilleros no atacaban a civiles - tan solo entrenaban a sus reclutas en política y tácticas de guerra-. Pero con el tiempo, las FARC se volvieron más violentas y desconfiadas de los demás. "Desde el comienzo de entrar en la organización, hasta el día que yo deserté, siempre me vine con preguntas", dice, preguntas sobre él, sus camaradas y las personas que daban las órdenes, particularmente, su disposición a matar a antiguos aliados. Pero Sánchez calló sus dudas, porque cuestionar las órdenes lo llevaría a la muerte. En vez de eso, ascendió en las filas, liderando eventualmente a unos 25 combatientes.

Para 2005, se había vuelto más desilusionado con las FARC. Le entregaron una lista con nombres de informantes sospechosos a los que le ordenaron debía de matar; la lista incluía a niños de 12 y 13 años, así como a dos personas que él conocía desde su infancia. Él le ordenó a sus tropas que lo hicieran - algo que lo atormenta hasta el día de hoy-. "Uno es el que lleva la carga", dice.
"Desde el

comienzo de

entrar en la

organización, hasta el día que yo deserté, siempre me vine con preguntas".
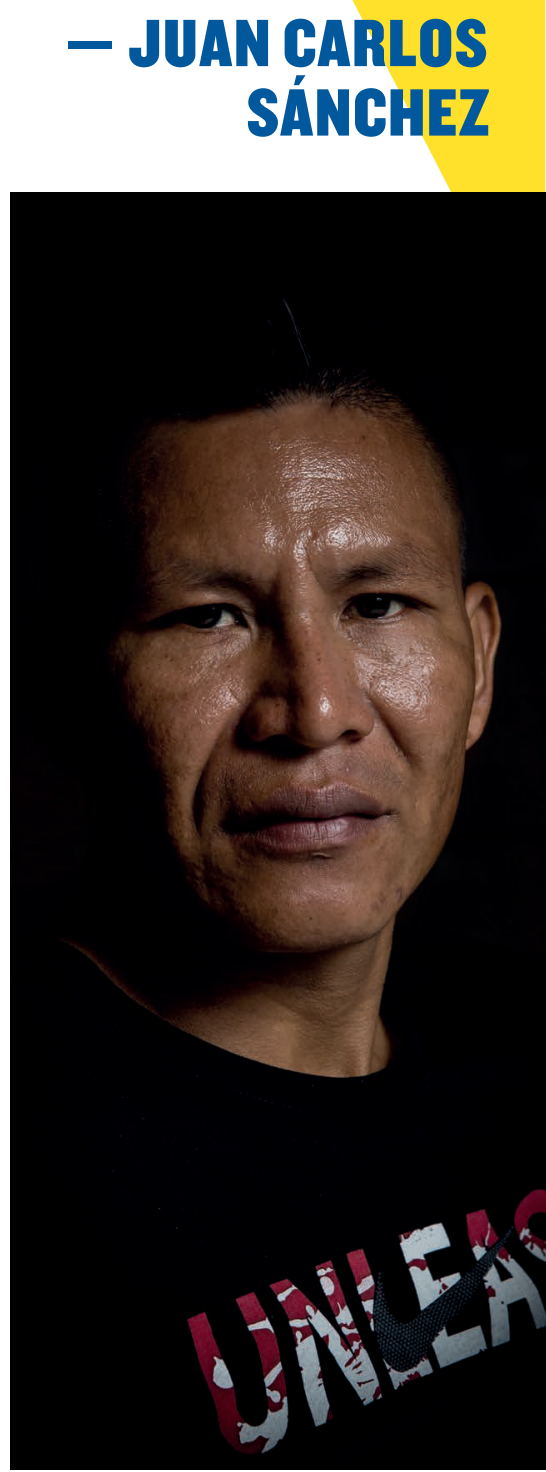

Luego, unos años después, los guerrilleros condenaron a su novia, también miembro de las FARC, por espionaje. Sánchez hizo planes para huir con ella, pero fue descubierto y tuvo que huir por su cuenta. Más tarde supo que ella había sido ejecutada.

Por tres años, Sánchez vivió escondido en Meta, viendo enemigos en todas partes. "Vivía en una zozobra permanente", dice. Eventualmente, un amigo le contó sobre el programa de rehabilitación del gobierno y se unió. Se mudó al Valle del Cauca y ahora trabaja en el campo para ganarse la vida. Él ha tenido consultas con un psicólogo y ha comenzado a leer la Biblia. "Entre los dos, me han ayudado a auto-perdonarme y a perdonar", dice.

En el hotel, Sánchez mira los vídeos de altercados intercalados con una serie de preguntas: le preguntan si las imágenes le molestan, o si algunas de las partes involucradas debe ser castigada. Luego trata de identificar las emociones a través de una serie de caras.

"Estamos observando qué tipo de errores cometen", dice Agustín Ibáñez, un neurocientífico de la Universidad Favaloro de Buenos Aires, Argentina, quien está administrando la prueba, una versión simulada de la misma prueba que ya le ha aplicado a unos 350 excombatientes colombianos. Ibáñez pretende discernir cómo el aislamiento de la sociedad y la exposición a la violencia pueden haber menoscabado su procesamiento emocional y su juicio moral ${ }^{1}$. Los excombatientes -tanto lo de las FARC, como los paramilitares- tienden a tener problemas para distinguir entre las emociones, especialmente el miedo y la ira. Aunque no está claro si estos efectos persisten fuera del laboratorio, a Ibáñez y a su equipo les preocupa que los problemas emocionales puedan hacerles la vida aún más difícil a los excombatientes, como le ha ocurrido a excombatientes en otros lugares.

Él y Eduar Herrera, un psicólogo cognitivo de la Universidad Icesi, en Cali, comenzaron esta línea de investigación en 2014, trabajando con un grupo de paramilitares encarcelados por crímenes de guerra. Habían matado a un promedio de 33 personas cada uno, y algunos se les encontró responsables de masacrar a cientos.

"La primera vez, estábamos muy asustados", recuerda Ibáñez. Los excombatientes no estaban esposados y se encontraron cara a cara con los investigadores. "Tienes la sensación de que podrían matar a todos, si así lo desearan”.

En 2017, los investigadores encontraron que una característica clave de los excombatientes es cómo juzgan la moralidad de una acción. La mayoría de los participantes condenarían un intento de envenenamiento, por ejemplo, incluso si no se lograra matar al objetivo. Pero el grupo de Ibáñez ha descubierto que es menos probable que los excombatientes condenen a alguien por un intento de asesinato fallido, razonando que si la víctima no murió, no hubo daño. Al mismo tiempo, es más probable que quieran castigar a las personas por daños que son claramente accidentales. Según su lógica, el resultado es más importante que la intención.

Basado en una pequeña muestra, parece que los paramilitares están más perjudicados en este sentido que los guerrilleros. Ibáñez dice que esta diferencia podría tener sentido: las personas que se unieron a los paramilitares por un salario podrían haber estado más atraídas hacia la violencia que aquellos que se unieron a 
la guerrilla por razones ideológicas, aunque no hay forma de probar esto. Estos datos sugieren que los programas de rehabilitación no deberían tratar a todos los excombatientes de la misma manera.

Trujillo también ha encontrado diferencias notables en sus participantes. En un estudio de 624 exguerrilleros y exparamilitares ${ }^{2}$, ella y sus colegas descubrieron que la capacidad de empatizar se dividía en 3 grupos: el 22\% de los excombatientes funcionaba de forma muy similar a personas que no habían experimentado la violencia; el 32\% tenía la capacidad de reconocer el dolor o la desgracia en los demás, pero no se veía tan afectado por ellos; y el resto no podía reconocer sentimientos como la angustia emocional en los demás, ni sentir empatía con ellos.

Los investigadores se preguntan si estos excombatientes -que se desmovilizaron voluntariamente- son similares a los 6.800 combatientes de las FARC que ingresaron al programa de reincorporación como parte del tratado de 2016, muchos de ellos por órdenes de sus comandantes. A diferencia de Sánchez, muchos siguen siendo decididamente ideológicos. Óscar Vega, por ejemplo, un excomandante de las FARC, delgado e intenso, que vive en la zona de tránsito cerca de Vista Hermosa, lleva a casi todas sus conversaciones al tema sobre las formas en que el gobierno y el sistema educativo de Colombia dañan a las personas. Él todavía vive por la causa. "Nuestros documentos y nuestra línea ideológica dice que por cualquier vía tenemos que llegar a la toma de poder, bien sea por la vía armada o bien sea por la vía política”, dice.

Trujillo está comparando varios tipos de terapias para determinar la mejor manera de ayudar a los excombatientes a mejorar su desempeño en las pruebas de empatía ${ }^{3}$. Ella y sus colegas están utilizando la electroencefalografía (EEG) para controlar la actividad cerebral de los excombatientes, con la esperanza de aprender cómo procesan la información ${ }^{4}$. En una investigación aún sin publicar, el equipo descubrió que los excombatientes son más rápidos en el reconocimiento de caras que los civiles -a pesar de que son más lentos en identificar las emociones que estas reflejan-. También son mejores en la realización de tareas de memoria que van acompañadas de imágenes violentas, como sangre o cadáveres. Las personas que los investigadores identificaron como víctimas de la violencia muestran el patrón opuesto: tales imágenes perturban su concentración y ralentizan sus respuestas. Los investigadores piensan que los circuitos neuronales de los excombatientes se han adaptado para reaccionar más rápido ante las amenazas.

El grupo de Trujillo asesora a la filial de Medellín de la ARN en su esfuerzo por rehabilitar a los excombatientes. Pero tratar de utilizar la ciencia para cambiar y hacer políticas puede ser como hacer esculturas con arena seca. "La investigación ha sido muy complicada porque es un tema muy nuevo,

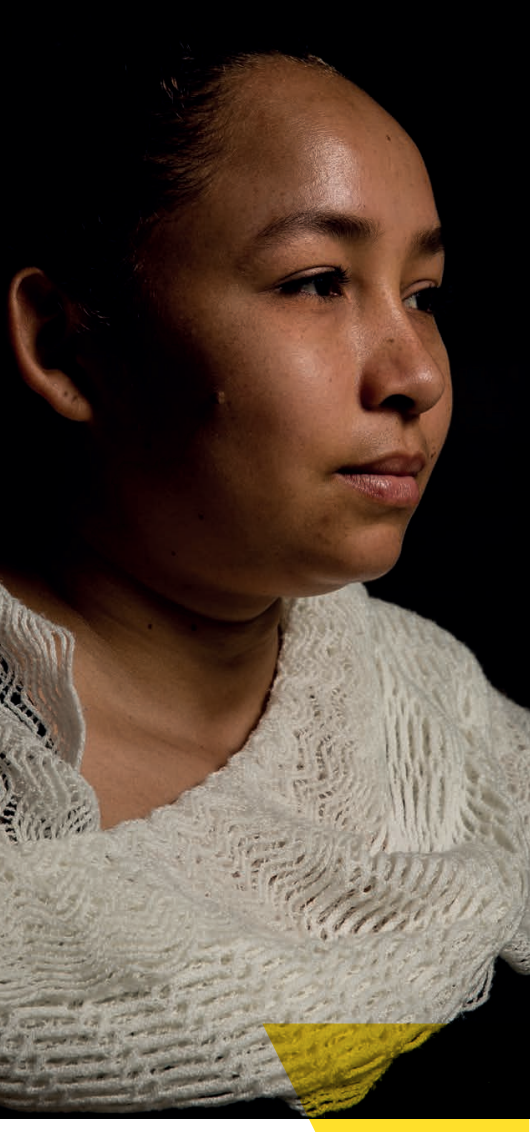

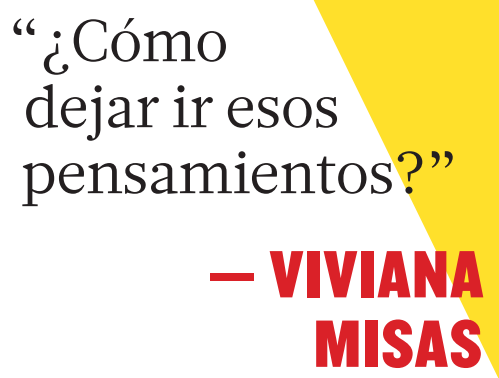

no solo para Colombia, sino también para la literatura sobre neurociencia cognitiva y social", dice. Los investigadores también se preocupan de que el gobierno pueda perder la paciencia. "Si no puedes encontrar algo sólido para demostrar lo que está sucediendo, no puedes proponer una solución", dice José David López, un ingeniero que trabaja con Trujillo en la interpretación de los datos de los EEG, en la Universidad de Antioquia. "Lo necesitan ahora, no en diez años".

\section{UNA BATALLA DESDE ADENTRO}

En su muñeca, Viviana Misas lleva el nombre del bebé que perdió mientras vivía con el Ejército de Liberación Nacional (ELN), otro grupo guerrillero de izquierda que todavía está activo en Colombia. Misas se unió al ELN a los 15 años para alejarse de su familia, y llegó a amar la ideología y la camaradería que le proporcionaba. Pero luego, durante una marcha difícil se cayó y se lesionó, y en el proceso tuvo un aborto espontáneo. Sus compañeros la abandonaron y ella terminó en el hospital por un largo tiempo. Desconfiando de su lealtad después de eso, un compañero combatiente - su mejor amigo- la traicionó y la delató al ejército colombiano. Ella fue capturada y aceptó desmovilizarse.

Al igual que Sánchez, no puede regresar a su casa en Medellín, por temor a que el ELN la mate como traidora. Aunque Misas disfruta de su trabajo como guía turística en el Valle del Cauca, la depresión le impide perseguir sus sueños. "Quisiera que cuando estoy triste ser una persona normal que solo se puso triste un momentito y no tiene pensamientos tan raros como los míos", dice. Ella no ha visto ningún psicoterapeuta, pero su perro le brinda cierto consuelo, al igual que la religión. Aún así, sus pensamientos se vuelven oscuros; quizás, dice ella, la verdadera razón por la que se unió al grupo fue porque esperaba ser asesinada. “ ¿Cómo dejar (ir) esos pensamientos?”, se pregunta.

Según los datos de la ARN, más del 90\% de los excombatientes en el programa tienen un problema psicosocial, como trastorno de estrés postraumático o ansiedad. El coordinador regional de ARN, Juan Fernando Vélez, dice que la salud mental es una de sus principales prioridades cuando trabaja con ellos. Los datos de Trujillo, dice, convencieron a su oficina de la necesidad de crear un programa especial de reintegración para personas con problemas psiquiátricos. "No podemos darle a la sociedad un individuo que no se siente bien consigo mismo", dice.

Joshua Mitrotti, quien dirigió la ARN durante tres años antes de renunciar en marzo, dice que los programas de la agencia se basan en los esfuerzos llevados a cabo en América Central en la década de 1990, que proporcionaron formación vocacional y educación para los grupos armados. El apoyo psicosocial es un componente integral, dice.

El programa de la ARN para guerrilleros y paramilitares que se desmovilizaron voluntariamente incluyó 30 meses de servicios psicosociales, a cargo de unos 300 psicólogos y 65 trabajadores sociales, en promedio. Hasta el momento, 20.490 personas han completado el proceso de reintegración y la ARN dice que más del 70\% se han reingresado exitosamente a la sociedad.

Pero con decenas de miles de excombatientes en Colombia, simplemente no hay suficientes profesionales de la salud mental capacitados para brindar atención básica, y mucho menos terapia cognitiva intensiva. Por ello, algunos temen que el programa de reintegración pueda estar brindando un tratamiento deficiente. "No es que estén haciendo las cosas mal, pero están incompletas", dice Herrera.

Uno de los desafíos es la dificultad de proporcionar tratamiento a adultos que no completaron la escuela primaria y no pueden leer, una habilidad requerida para algunas de las terapias habituales.

Mitrotti dice que la ARN ha estado ajustando los enfoques para hacerlos más apropiados. Según la ARN, el 30\% de las personas que acudieron a los servicios psicosociales el año pasado lo hicieron sin ningún incentivo 


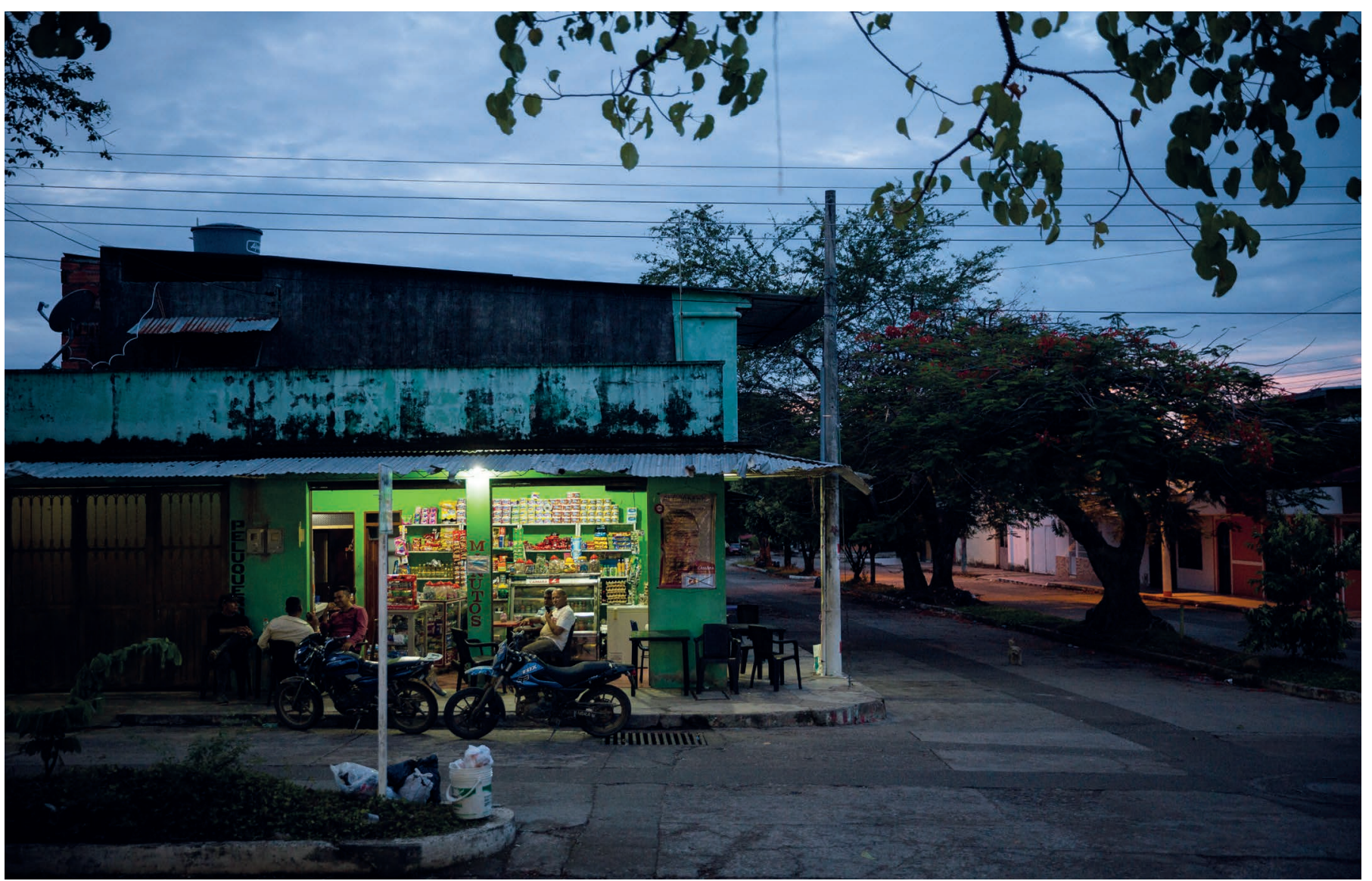

Con una economía lenta y una controversia continua sobre el acuerdo con las FARC, muchos en Colombia tienen sombrías esperanzas para el futuro.

- monetario (los excombatientes a menudo reciben un estipendio por participar en los programas). "No vienen porque se les paga, sino porque creen que necesitan el apoyo de nuestros profesionales", dice Mitrotti.

Sin embargo, la ayuda para los miembros de las FARC que recién se han desmovilizado ha tardado en llegar. Andrés Restrepo, un sociólogo que trabaja en una zona de transición en Caquetá, dice que los excombatientes de las FARC no están recibiendo ningún tipo de atención de salud mental. Restrepo dice que la ARN les ha prometido la llegada de seis psicólogos a la región, pero incluso eso no sería suficiente para atender a los 1.000 excombatientes y a sus familias que viven allí ahora.

Restrepo teme que si estos individuos no se encuentran psicológicamente estables, el rechazo de la sociedad-incluidas sus propias familias-podría llevarlos nuevamente a la violencia. "Nadie les ayudó a imaginar una vida sin armas", dice.

\section{UN FUTURO INCIERTO}

En Piñalito, un pequeño y polvoriento pueblo de casas de madera fluorescentes, en las afueras de Vista Hermosa, los civiles aún se están acostumbrando a la paz. "Es genial, no hay personas muertas”, dice Carlos García, un comerciante jubilado de edad avanzada. Recuerda escuchar de forma cotidiana los disparos, justo afuera de su puerta, cuando las FARC combatían a los paramilitares.
Ahora las calles son tranquilas y la gente visita los cafés. A algunos les faltan piernas - Colombia tiene una de las tasas más altas de víctimas de minas terrestres en el mundo, y Meta es una de las regiones más minadas-. Con el trasfondo de una ofensiva gubernamental contra el tráfico de cocaína, la caída de

\section{G adie les imaginar una vida sin armas".}

los precios del petróleo y el aumento del temor de que la paz sea solo temporal, la población de Piñalito parece tener pocas esperanzas para el futuro.

Y el acuerdo de paz en sí mismo está amenazado. Este mes, Colombia celebrará su elección presidencial, y el tema clave es si se debe renegociar el acuerdo para que sea menos favorable para las FARC. Muchos de los guerrilleras, mientras tanto, están perdiendo la fe en el proceso. Algunas de las zonas de tránsito a las que enviaron a los miembros de las FARC a vivir por un tiempo todavía no tienen agua corriente ni saneamiento. Y los programas de desarrollo agrícola y vocacional han tardado en arrancar. En todo el país, más de la mitad de los guerrilleros han abandonado estas zonas, optando por jugarse la suerte en una sociedad que no es segura para ellos. Desde el acuerdo, cientos de exmiembros de las FARC han sido asesinados.

A medida que los excombatientes vuelven a la sociedad o se retiran a la jungla, los expertos se preocupan por el estigma que llevan - de estar afiliados a las FARC y el de las enfermedades mentales-. Matallana espera que una de las cosas que su investigación pueda hacer sea mostrar al público cómo el trauma afecta tanto a excombatientes como a civiles.

Los recursos son escasos y el problema es inimaginablemente complejo, dice Vélez. En última instancia, dice, el éxito de Colombia depende de la voluntad de su gente y de su capacidad para hacer las paces con el pasado. "No hay fórmulas mágicas", dice. "Lo único que debemos entender es que todos necesitan -merecen- una segunda oportunidad".

Sara Reardon trabaja como periodista para Nature desde Washington D.C. El Centro Pulitzer para el Reporteo de Crisis proporcionó el financiamiento del viaje para llevar a cabo este reportaje.

1. Baez, S. et al. Nature Human Behav. 1,0118 (2017).

2. Trujillo, S. P. et al. J. Peace Psychol. https://doi. org/10.1037/pac0000255 (2017).

3. Trujillo, S. et al. Front. Psychol. 8, 510 (2017).

4. Tobón, C. et al. Soc. Neurosci. 10, 153-165 (2015). 